\title{
Gum Infection, CTCAE
}

National Cancer Institute

\section{Source}

National Cancer Institute. Gum Infection, CT CAE. NCI Thesaurus. Code C143523.

A disorder characterized by an infectious process involving the gums. 